\title{
INFLUENCE OF MAGNESIA ON THE STRUCTURE AND PROPERTIES OF BIOACTIVE GLASSES
}

\author{
S. J. Watts ${ }^{1,2}$, R. G. Hill ${ }^{1 *}$, M. D. O’Donnell ${ }^{1,2}$ and R. V. Law ${ }^{* 2}$ \\ ${ }^{1}$ Department of Materials, Imperial College, London, SW7 2AZ, UK \\ ${ }^{2}$ Department of Chemistry Imperial College, London, SW7 2AZ, UK \\ *Corresponding authors: E-mail r.law@imperial.ac, r.hill@imperial.ac.uk, \\ Tel: +44(0)20 7594 5860, +44(0)207594 6783 .
}

\begin{abstract}
\end{abstract}
Five bioactive glasses based on $49.5 \mathrm{SiO}_{2}-1.1 \mathrm{P}_{2} \mathrm{O}_{5}-(23.0(1-x)) \mathrm{CaO}-x \mathrm{MgO}-$ $26.4 \mathrm{Na}_{2} \mathrm{O}$ mol. \% were synthesised where $\mathrm{CaO}$ was replaced progressively on a molar basis by $\mathrm{MgO}$ (where $0 \leq x \leq 1$ ). The glasses were characterised by ${ }^{31} \mathrm{P}$ and ${ }^{29} \mathrm{Si}$ magic angle spinning nuclear magnetic resonance (MAS NMR) spectroscopy, dilatometry, differential thermal analysis (DTA) and density measurements with the aim of gaining a comprehensive understanding of the structure-property relationships.

The ${ }^{31} \mathrm{P}$ NMR spectra of the glasses exhibited well-defined resonances at $c a .9$ to $14 \mathrm{ppm}$, corresponding to a $\mathrm{Q}^{0}$ orthophosphate environment. Full substitution of $\mathrm{MgO}$ caused a downfield shift of $c a$. 5ppm, implying the preferential association of sodium with the orthophosphate species. The ${ }^{29} \mathrm{Si}$ NMR spectra exhibited a peak at ca. 79ppm, indicating a $\mathrm{Q}^{2}$ silicon species, along with a shoulder at $c a$. 90ppm, corresponding to a $\mathrm{Q}^{3}$ species. On addition of $\mathrm{MgO}$, the $\mathrm{Q}^{3}$ shoulder was seen to progressively increase in magnitude. These results suggest that $\mathrm{MgO}$, rather than depolymerising the silicate network by acting as a network modifier, is behaving in 
part, as an intermediate oxide. Deconvolution of the ${ }^{29} \mathrm{Si}$ NMR peaks suggest that, although $86 \%$ of the magnesium oxide is acting traditionally as a network modifying cation, up to $14 \%$ of the magnesium oxide is entering the silicate network as tetrahedral, $\mathrm{MgO}_{4}$, removing network modifying ions for charge compensation and resulting in the observed polymerisation of the silicate network. Correspondingly, both the glass transition temperature and dilatometric softening point values were seen to decrease whilst the thermal expansion coefficient values rose, with increasing $\mathrm{MgO}$ content. This was due to the significantly lower bond strength, of $\mathrm{Mg}-\mathrm{O}$ compared to $\mathrm{Si}-\mathrm{O}$, weakening the glass network. 


\section{Introduction}

In 1969 Hench et al. [1, 2] developed the first amorphous, inorganic bioactive material, Bioglass ${ }^{\circledR}$, based on a soda-lime phospho-silicate glass. Most materials, at best, elicit a neutral response when implanted into the human body. Bioglass ${ }^{\circledR}$ however was seen to create a positive response by promoting the deposition of the body's natural bone substance, hydroxyapatite. Although it is well recognised that compositional modifications affect the bioactivity of glasses, there is very little understanding of the composition-structure-property relationships that result in such behaviour. The purpose of this investigation, therefore, is to study these fundamental relationships with respect to a component often found in bioactive glass compositions - magnesium oxide.

Network connectivity (NC) is defined as the average number of bonds that link each repeat unit in the silicate network and is based on the relative number of network forming oxides (those which contribute bridging oxygen (BO) species) and number of network modifying species (those which result in the formation of nonbridging oxygens (NBOs)) [1, 2]. To determine the level of bioactive behaviour using such a model, it is critical to have a structural understanding of each species within the glass. Without such knowledge, assessing the bioactive behaviour of a specific glass composition is extremely problematic. Previous studies, in particular using nuclear magnetic resonance (NMR) - a useful technique for probing the short range order in glasses, have clarified the structural role of silicon, aluminium, sodium and calcium in the glass network [3-5]. Thus predicting the bioactive behaviour of glasses containing these particular elements (in any composition), using the network connectivity model, becomes surprisingly straight forward. Therefore, this investigation aims to add to understanding of the network connectivity model with 
respect to bioactive glasses by clarifying magnesium's structural role within such compositions.

A number of mechanisms have been proposed to explain the bioactive behaviour of glasses and glass-ceramics. The first and most widely accepted mechanism, is that associated with the research of Hench and co-workers $[6,7]$. There are, however, alternative theories on the mechanism of glass degradation and bone bonding behaviour from Kokubo and co-workers [8], Andersson and co-workers [9], Li and co-workers [10] and Hill and co-workers [11].

Hill suggested an alternative viewpoint with respect to the degradation of bioactive glasses, realising the inadequacy of the mechanism proposed by Hench in predicting the reactivity of a bioactive glass as a function of its composition $[11,12]$. As with Strnad [13] and Rawlings [14], Hill recognised the importance of the degree of disruption of a glass in determining its bioactivity. Following the approach of Holliday and Ray $[15,16]$, viewing silicate glasses as inorganic polymers of oxygen cross linked by silicon, Hill introduced the concept of network connectivity to the field of bioactive glasses. Properties including thermal expansion, ability to undergo phase separation, surface reactivity and solubility all can be explained on the basis of the degree of polymerisation of the silicate network, network connectivity and the inorganic polymer model [11].

As bioactivity arises from the ability of a glass to undergo surface dissolution in a physiological environment, the degree of solubility of a glass composition must be critical in determining its bioactivity. The application of the inorganic polymer model to a glass structure, therefore, allows its bioactivity to be predicted, with a glass of low network connectivity considered to be highly disrupted and bioactive, provided it does not give rise to toxic degradation products. [17]. All of the very reactive bone 
bonding bioactive glass compositions have network connectivities below or close to 2.00 , with the most widely studied $45 \mathrm{~S} 5^{\circledR}$ glass having a NC value of 1.90 .

Magnesia has often been incorporated into bioactive glasses [18-29] however, despite this work, there have been few systematic studies into the structural role of $\mathrm{MgO}$ and its resultant bioactive behaviour. Conventionally magnesium oxide is thought to behave like calcium oxide, as a network modifier, within a silicate glass structure. However, on examination of a number of elemental properties such as charge to size ratio and Pauling electronegativity, $\mathrm{Mg}^{2+}$ falls on the boundary between being a network modifier and an intermediate oxide. Circumstantial evidence exists that $\mathrm{MgO}$ may act as intermediate oxide in highly disrupted silicate glasses from the extension of the glass forming region in ternary diagrams towards lower $\mathrm{SiO}_{2}$ mole fractions and this point has been recognised by McMillan [30]. Stebbins and Fiske [31], Oliveira [24], Kohara [32], Karakassides [33], Dietzel [34], Shimoda [35] and Doweidar [36] acknowledge the possibility of $\mathrm{MgO}$ acting as an intermediate oxide and all comment on the importance of clarifying its structural role within a glass.

It is suggested that the lack of structural understanding of magnesium within glasses has lead to the many conflicting views on its contribution with respect to bioactivity. $\mathrm{MgO}$ has been documented as decreasing apatite formation in SBF [26] but also, on the other hand, improving the early stages of mineralization [24] and contributing to an intimate contact with living tissue. It is proposed that these conflicting reports call for a comprehensive study into magnesium and bioactivity.

Magnesium is involved in over 300 chemical reactions in the body and, among other things, is known to activate phagocytosis and regulate active calcium transport. As a result, there has been a growing interest in its role, not only in wound healing, but also in bone metabolism with a two year study highlighting the positive effects on 
fracture prevention and bone density $[37,38]$. Such influential roles with respect to bone metabolism and wound healing are extremely attractive when considering the potential end applications of magnesium containing bioactive glass compositions. This paper therefore, endeavours to comprehend magnesium's role within a bioactive glass structure and understand the composition-structure-property relationships that exist in such a structure.

\section{Experimental}

\subsection{Glass melting}

Magnesium oxide was substituted for calcium oxide, on a molar basis, in a previously studied glass composition [5]. The calculated network connectivity values were kept constant, at 2.13 , to eliminate any influence due to network disruption and thus provide a greater understanding of the underlying composition-property relationships in the glass. The resulting glass compositions are given in Table 1.

\footnotetext{
$* *$ Table $1 * *$
}

These are nominal batched values. For the NC(NMR) calculation, we assumed, for the sake of simplicity, that $\mathrm{Mg}$ was only in the four co-ordinate state and went into the network as a tetrahedral $\mathrm{MgO}_{4}$ species. This was based on the assumption that $\mathrm{Mg}$ was behaving as it is found in the mineral, akermanite $\left(\mathrm{Ca}_{2} \mathrm{MgSi}_{2} \mathrm{O}_{7}\right)$ or spinel $\mathrm{MgAl}_{2} \mathrm{O}_{4}[31,39-41]$.

All glasses were prepared using reagent grade chemicals for each case $\left(\mathrm{SiO}_{2}\right.$, $\mathrm{P}_{2} \mathrm{O}_{5}, \mathrm{CaCO}_{3}, \mathrm{Na}_{2} \mathrm{CO}_{3}$, and $\mathrm{MgCO}_{3}$ ). It is important to note that the addition of $\mathrm{P}_{2} \mathrm{O}_{5}$ 
was always made last due to its extremely hydroscopic nature. The compositions were melted in platinum-rhodium or platinum-gold crucibles at $1450^{\circ} \mathrm{C}$ for one and a half hours. The melts were then rapidly quenched in cold water and the glass frit collected in a sieve and dried overnight at $120^{\circ} \mathrm{C}$. The dried frit was then ground in a Gyro Mill (Glen Creston) for seven minutes and sieved for forty five minutes in a mechanical shaker to obtain $<45 \mu \mathrm{m}$ particles. Rods and discs were also cast for each composition by re-melting the glass frit for half an hour at approximately $1470^{\circ} \mathrm{C}$. The glass was then poured into a pre-heated graphite mould and annealed overnight at $20^{\circ} \mathrm{C}$ below the glass transition temperature $\left(\mathrm{T}_{\mathrm{g}}\right)$.

\subsection{Magic Angle Spinning Nuclear Magnetic Resonance (MAS NMR)}

${ }^{29} \mathrm{Si}$ MAS NMR and ${ }^{31} \mathrm{P}$ MAS NMR were used to analyse the glass samples using a Bruker DSX FT-NMR spectrometer operating at a Larmor frequencies of 39.77MHz and $81.9 \mathrm{MHz}$ respectively. Samples were packed into a $4 \mathrm{~mm}$ zirconia rotor and spun at the magic angle to remove anisotropy effects. The ${ }^{29} \mathrm{Si}$ and ${ }^{31} \mathrm{P} \mathrm{MAS}$ NMR spectra of the glasses were recorded at spinning frequencies from $3-12 \mathrm{kHz}$ using pulse acquisition of $\pi / 2$ for both silicon and phosphorus. The ${ }^{29} \mathrm{Si}$ and ${ }^{31} \mathrm{P}$ MAS NMR samples were spun with a recycle delay time set to generally 2 s (this however was increased to $60 \mathrm{~s}$ if the glass species were not thought to be completely relaxed). All spectra were recorded at an ambient probe temperature with ${ }^{29} \mathrm{Si}$ referenced relative to polydimethylsiloxane (PDMS) $(-22.3 \mathrm{ppm})$ and $85 \% \mathrm{H}_{3} \mathrm{PO}_{4}(0 \mathrm{ppm})$ for ${ }^{31} \mathrm{P}$. Peak fitting to determine the peak areas for NC(NMR) was done by WinNMR program (Bruker). 


\subsection{X-Ray Diffraction (XRD)}

A Phillips Powder Diffractometer with a copper $\left(\mathrm{Cu} \mathrm{K}_{\alpha}\right)$ x-ray source (Philips PW 1700 series diffractometer, Philips, Endhoven, NL) was used to characterise the glass samples. The powder samples $(<45 \mu \mathrm{m}$ particle size $)$ were scanned between $2 \theta=$ $5-80^{\circ}$ with a step size of $2 \theta=0.04^{\circ}$, in order to investigate the amorphous nature of each glass.

\subsection{Differential Thermal Analysis (DTA)}

The glasses were characterised by simultaneous DTA/TGA using a Stanton Redcroft DTA 1600. Alumina was used as the reference material and both reference and sample were contained within platinum-rhodium alloy crucibles. The $<45 \mu \mathrm{m}$ particle size powders were heated from room temperature to $1300^{\circ} \mathrm{C}$, at a heating rate of $10^{\circ} \mathrm{C} / \mathrm{min}$, in an inert argon atmosphere. The glass transition temperature $\left(\mathrm{T}_{\mathrm{g}}\right)$ and crystallisation temperatures $\left(\mathrm{T}_{\mathrm{c}}\right)$ for each glass were then obtained from the corresponding traces.

\subsection{Dilatometry}

A Netzsch Dil 402C dilatometer was used to determine $T_{g}$, the dilatometric softening temperature $\left(\mathrm{T}_{\mathrm{s}}\right)$ and the thermal expansion coefficient (TEC) for each glass. $25 \mathrm{~mm} \times 6 \mathrm{~mm}$ cut samples were analysed from room temperature to $\mathrm{T}_{\mathrm{s}}+30^{\circ} \mathrm{C}$ at a heating rate of $5^{\circ} \mathrm{C} / \mathrm{min}$. The TEC and $\mathrm{T}_{\mathrm{s}}$ were determined by using the system software and the TEC taken between $25^{\circ} \mathrm{C}$ and $400^{\circ} \mathrm{C}$. 


\subsection{Density Measurements}

Using Archimedes principle the density of each cast glass sample, at room temperature, was determined. The weight of each glass was measured in air and in distilled water using an accurate balance $( \pm 0.1 \mathrm{mg})$. The weight was measured three times and an average taken in order to minimise the sources of error. Care was taken to make sure that all of the cast samples were bubble free and that the glass samples were fully wetted when immersed in the distilled water. The oxygen density was then calculated from these bulk density values, according to Ray [16]. 


\section{Results and Discussion}

\subsection{Magic Angle Spinning Nuclear Magnetic Resonance (MAS NMR) Spectroscopy ${ }^{31}$ P MAS NMR}

The ${ }^{31} \mathrm{P}$ MAS NMR spectra show a single symmetric resonance, as shown in Fig. 1, with a chemical shift range in the region $8.2-12.7 \mathrm{ppm}$ and with an approximately constant linewidth of $c a .600 \mathrm{~Hz}$.

$$
\text { **Fig. } 1 * *
$$

Table 2 summarises the peak positions and full width half maximums (FWHM).

$$
* * \text { Table } 2 * *
$$

The ${ }^{31} \mathrm{P}$ NMR chemical shifts for the magnesium substituted series correspond to the existence of an orthophosphate environment with no evidence of the existence of Si-O-P bonds, agreeing with Lockyer et al. [3] and Elgayar et al. [5]. Previously phosphorus was assumed to enter the glass network forming Si-O-P bonds [42]. However, the absence of peaks at ca. $-215 \mathrm{ppm}$ in the ${ }^{29} \mathrm{Si}$ MAS NMR and ca. -33 to $-40 \mathrm{ppm}$ in the ${ }^{31} \mathrm{P}$ MAS NMR spectrum rule this out [43]. However the existence of orthophosphate species, along with the fact that the glasses are optically clear, suggest that the phosphorus in the glass may have undergone amorphous phase separation into a sub-micron (below light scattering dimensions) phosphate phase. 
Initially we observe the ICIE1 glass to have a chemical shift of $c a$. 8.2ppm between that of a $\mathrm{Na}_{3}\left(\mathrm{PO}_{4}\right)$ species at $14 \mathrm{ppm}[44]$ and a $\mathrm{Ca}_{3}\left(\mathrm{PO}_{4}\right)_{2}$ species at $0 \mathrm{ppm}$ or $3 p p m[44,45]$, thus implying that both types of modifier ion are associated with the orthophosphate unit. As we move through the series, it would be expected that substituting magnesium for calcium would simply result in the direct replacement in the phosphate environment of $\mathrm{Ca}$ for $\mathrm{Mg}$ as reported by Oliveira et al. [24], or in the case of Lockyer et al. [3] and Elgayar et al. [5], a mixed, non preferential, two cation orthophosphate at a ratio consistent with that of the overall glass. Although $\mathrm{Mg}^{2+}$ (1.31) is slightly more electronegative, on the Pauling scale, than $\mathrm{Ca}^{2+}(1.00)$ and $\mathrm{Na}^{+}$ (0.93), the observed experimental shift is contrary to what is expected [3], with the final, fully substituted composition shifting to a more positive (away from 0ppm) region of the spectra $c a \cdot 12.7 \mathrm{ppm}$ - close to that associated with a pure sodium orthophosphate species.

$$
* * \text { Fig. } 2 * *
$$

This positive shift (away from 0ppm - Fig. 2), towards a sodium orthophosphate type species and away from magnesium phosphate $(0.5 \mathrm{ppm}$ for the amorphous $\mathrm{Mg}_{3}\left(\mathrm{PO}_{4}\right)_{2}$ form [46, 47]), implies that as magnesium is added, at the expense of calcium, sodium progressively preferentially associates with the phosphate phase. It appears there is only a minimal association of the magnesium with the phosphate phase and is an indication that an increase in magnesium content may lead to more $\mathrm{Mg}^{2+}$ ions participating in the silicate phase (this point will be discussed in greater detail later). 
Fig. 3 illustrates the ${ }^{29} \mathrm{Si}$ MAS NMR spectra for the magnesium substituted series of glasses. The spectrum for $0 \%$ magnesium substituted glass consists of a peak with a resonance maximum $c a$. $-79 \mathrm{ppm}$. The $25 \%$ magnesium substituted glass displays a similar spectrum, however, as we move through the series to the $50 \%$ magnesium substituted glass, the presence of a shoulder to the right of the peak $c a$. 90ppm becomes apparent, moving the centre of gravity of the peak to the right. This shoulder becomes more pronounced across the series. It is assumed that the development of the asymmetric line shape and right hand shoulder, across the series, is a progressive superposition of two overlapping signals. The fitting data of these two peaks, from Gaussian deconvolution, can be found in Table 2. With magnesium substitution, the $\mathrm{Q}^{3}$ shoulder grows from $17 \%(0 \% \mathrm{Mg}$ substitution) to $41 \%$ (100\% $\mathrm{Mg}$ substitution) area of the signal. This is clear evidence that, as magnesium is added, a proportion of the magnesium ions forms tetrahedral, $\mathrm{MgO}_{4}$, which requires charge balancing cations. [39, 40] These $\mathrm{MgO}_{4}$ units remove modifying ions (e.g. $\mathrm{Ca}^{2+}$ ) from the silicate network resulting in the observed polymerisation going from $\mathrm{Q}^{2}$ to $\mathrm{Q}^{3}$.

In spite of such signal overlap, the ${ }^{29} \mathrm{Si}$ NMR spectra of the magnesium substituted series reveal that they are all predominantly populated by $\mathrm{Q}^{2}$ silicate species with the addition of $\mathrm{Q}^{3}$ species at higher magnesium contents. There seems to be no evidence of any further $Q$ species within the series, therefore a binary distribution model for the glasses is suggested, agreeing with earlier work by Lockyer et al. [3] and Elgayar et al. [5]. It is noted, however, from previous work that more 
than two $\mathrm{Q}^{\mathrm{n}}$ species can coexist at all compositions, suggesting a model based on the disproportionation reaction shown by equation (1) [23, 48].

$$
Q^{n}=Q^{n-1}+Q^{n+1}
$$

Closer inspection of the magnesium substituted glass spectra illustrate no evidence of peaks at -105 or $-60 \mathrm{ppm}$, therefore it can be concluded that there are little or no $\mathrm{Q}^{4}$ or $\mathrm{Q}^{0}$ species present. As noted by Elgayar et al. [5], difficulty can arise with respect to the identification of $\mathrm{Q}^{1}$ silicate species with ${ }^{29} \mathrm{Si}$ spectra alone due to the close proximity of $\mathrm{Q}^{2}$ species (-70ppm $\mathrm{Q}^{1} \rightarrow-80 \mathrm{ppm} \mathrm{Q}^{2}$ ) [49]. Further hindrance can also occur in mixed metal glasses due to the spread of ${ }^{29} \mathrm{Si}$ chemical shifts for each $\mathrm{Q}^{\mathrm{n}}$ species, for example $\delta_{\mathrm{Si}}=-76 \mathrm{ppm}$ for $\mathrm{Q}^{2}(\mathrm{Na})[50]$ and $\delta_{\mathrm{Si}}=-81.5 \mathrm{ppm}$ for $\mathrm{Q}^{2}(\mathrm{Ca})$ [51]. Therefore, it is questionable as to whether any $\mathrm{Q}^{1}$ species are being masked due to the overlap of silicon chemical shifts. At present this remains unanswered however, for the purpose of this study, a binary distribution of $\mathrm{Q}^{2}$ and $\mathrm{Q}^{3}$ is assumed.

Using Doweidar's model it is assumed that throughout the series of glasses the binary distribution of $\mathrm{Q}^{2}$ and $\mathrm{Q}^{3}$ species will remain constant. Also, using network connectivity calculations to model the glass structure, the connectivity is calculated to remain constant at 2.13 (calculated assuming $\mathrm{P}$ is present as orthophosphate as illustrated from the previous ${ }^{31}$ P MAS NMR data). Both of these models presume that magnesium acts as a network modifier. Therefore, in a direct substitution of magnesium for calcium it is predicted that the connectivity/Q structure will remain constant, due to both cations creating the same number of NBOs. This would then result in a series with corresponding constant ${ }^{29} \mathrm{Si}$ NMR chemical shift values (disregarding any shift due to the shielding effects of $\mathrm{Mg}^{2+}$ and $\mathrm{Ca}^{2+}-$ Galliano et al. 
[52] did not find any changes in the ${ }^{29} \mathrm{Si}$ NMR spectra when replacing cations in a glass series containing silicon, phosphorus and alkaline earth elements).

However, progressive formation of a right hand shoulder is observed with a peak resonance associated with that of a $Q^{3}$ species. This is contradictory to the network connectivity model and implies the progressive polymerisation of the glass structure is a result of magnesium entering the silicate network.

**Fig. $4 * *$

Fig. 4 illustrates a cartoon of the glass structure. It highlights the preferential association of sodium ions with the phosphate phase, as shown from ${ }^{31} \mathrm{P}$ NMR data, and the tendency of magnesium to enter the silicate network as $\mathrm{MgO}_{4}$ tetrahedra, charge balanced by calcium / sodium ions. Though shown here as a tetrahedral in Fig. 4, other higher co-ordinate states e.g. octahedral are possible for $\mathrm{Mg}$, though they would be outside of the network [40].

\subsection{Network connectivity}

Table 1 shows the calculated network connectivity of the glasses, assuming i) the phosphate enters the network (NC) or ii) phase separation into an orthophosphate phase (NC'). As we have said earlier $\mathrm{NC}^{\prime}$ is a more reasonable assumption for network connectivity as there is little evidence for $\mathrm{Si}-\mathrm{O}-\mathrm{P}$ bonds present. An empirical determination of the network connectivity was derived from peak fitting of the $\mathrm{Q}^{2}$ and $\mathrm{Q}^{3}{ }^{29} \mathrm{Si}$ MAS NMR data (Fig. 3), the NC(NMR), and is also given in Table 1. The $\mathrm{NC}(\mathrm{NMR})$ values are clearly higher, deviating more as magnesium is substituted into the series (Fig. 5). 
**Fig. $5^{* *}$

The deviation from the linear $\mathrm{NC}^{\prime}$ must be due to the formation of tetrahedral $\mathrm{MgO}_{4}$, species which goes into the network, will require sodium and / or calcium ions for charge balancing. This removes cations from the silica network and has the net effect of increasing the network connectivity. These $\mathrm{NC}(\mathrm{NMR})$ values were used to calculate the proportion of magnesium acting either as modifiers and/or those forming tetrahedral $\mathrm{MgO}_{4}$. From the difference between the calculated $\mathrm{NC}$ ' and the $\mathrm{NC}(\mathrm{NMR})$, it is possible to calculate the amount of tetrahedral $\mathrm{MgO}_{4}$. In this calculation, however, we have assumed, for the sake of simplicity, that $\mathrm{Mg}$ is only present as tetrahedral, $\mathrm{MgO}_{4}$. Fig. 6 shows the absolute molar amount of magnesium acting as a network former, in a tetrahedral state, for all the glass compositions.

$$
* * \text { Fig. } 6 * *
$$

However, as the amount of magnesium increases when it is substituted for calcium, the proportion in the network as compared to the proportion acting as modifiers is actually constant across the series; $\approx 14 \%$ of the magnesium enters the network as tetrahedral $\mathrm{MgO}_{4}$ whereas around $86 \%$ occupies the traditional modifier role regardless of the composition.

\subsection{Physical Properties}

XRD of the powdered samples illustrated that they were all amorphous in nature. Fig. 7 displays the resultant DTA traces for the magnesium substituted glasses. 
**Fig. $7 * *$

In general the DTA curves for samples ICIE1 to ICIE1-75Mg have two transitions - one due to a $\mathrm{T}_{\mathrm{g}}$, with a negative deviation from the baseline, and one due to an exothermic crystallisation event $\left(\mathrm{T}_{\mathrm{c}}\right)$ (Fig. 8). There is a possible second exotherm in the ICIE1 and ICIE1-25Mg glasses corresponding to a second crystallisation temperature. Also the ICIE1-100g glass shows only one transition due to a glass transition.

$$
\text { **Fig. } 8 * *
$$

The behaviour of $\mathrm{T}_{\mathrm{g}}$ suggests that the addition of $\mathrm{MgO}$ results in a "weakening" of the glass network. As Mg content increases in the glass, the decrease in $\mathrm{T}_{\mathrm{g}}$ is attributed to magnesium entering the network as tetrahedral magnesium species, $\mathrm{MgO}_{4}[35,40]$. We hypothesise that the newly formed $\mathrm{Si}-\mathrm{O}-\mathrm{Mg}$ bonds have, on average, a significantly lower bond strength with respect to $\mathrm{Si}-\mathrm{O}-\mathrm{Si}$ bonds in the silicate chain and therefore, as a result, resulting in the observed reduction in $\mathrm{T}_{\mathrm{g}}$. Dowty studied the vibrational spectrum of akermanite, a calcium magnesium silicate $\left(\mathrm{Ca}_{2} \mathrm{MgSi}_{2} \mathrm{O}_{7}\right)$ which contains tetrahedral $\mathrm{MgO}_{4}$ units [53]. The bond force constant of the $\mathrm{Mg}-\mathrm{O}$ bond in akermanite was found to be lower than in $\mathrm{MgO}$ and significantly lower than a Si-O bond: $2.00,3.48$ and $9.24 \mathrm{Ncm}^{-1}$ respectively [53, 54]). This phenomenon is also noted by Linati et al. [55], however the study was on the role of zinc rather than magnesium in a similar glass series. However, it is interesting to note that magnesium and zinc are similar ions with respect to charge and ionic radius, 
$0.72 \AA$ and $0.74 \AA$ accordingly, and it is suggested that the two behave in a similar manner within glass systems [56].

Fig. 9 highlights the behaviour of TEC values with a slight increase after 20 mole $\%$ substituted magnesium, attributed to magnesium entering the network and the weakening of the glass structure allowing greater thermal expansion. Appen's predictions for decreasing thermal expansion with the substitution of the higher polarising magnesium are also plotted on Fig. 9.

$$
\text { **Fig. } 9 * *
$$

The experimental deviation from Appen's trend at $>20 \mathrm{~mole} \%$ can be ascribed to the change in the structural role of magnesium oxide, from a modifier to an intermediate oxide through the series.

Fig. 10 illustrates the experimental density values along with Doweidar's predicted density values. Doweidar postulated that the density of a glass can be correlated with the volume of its structural units using the conventions of the $\mathrm{Q}^{\mathrm{n}}$ units, with the addition of network modifying oxides to calculate the density of a glass [5, $36,57]$.

$$
* * \text { Fig. } 10 * *
$$

As magnesium is substituted for calcium, the smaller ionic radius [58] and lighter molar mass result in the observed decrease in bulk glass density. This agrees with Doweidar's predictions, confirming that the glasses are predominantly $\mathrm{Q}^{2}$ in structure. Deviations however are observed from $>20$ mole $\%$ which could be assigned 
once again to the change in structural role of magnesium, switching from a modifier to an intermediate through the series.

The substitution of magnesium for calcium is seen to result in a directly proportionate relationship with oxygen density (Fig. 11).

\section{**Fig. $11 * *$}

This could be attributed equally to the effect of magnesium as a modifier, the higher polarising power due to the charge-to-size ratio of $\mathrm{Mg}$, binding to the NBOs more closely, or magnesium taking part in the silicate network, with the resultant loss of NBOs. It is important to note that, on entering the network, magnesium would act to weaken the network and to simultaneously decrease the number of NBOs and increase NC. It is argued, however, that the lower bond strengths would contribute to the oxygen density to a much smaller extent than the loss in NBOs.

According to Fig. 12 crystallisation temperature linearly increases with increasing $\mathrm{MgO}$ content. Noticeably at low $\mathrm{MgO}$ content there is a sharp pronounced crystallisation peak, which reduces in magnitude and broadens as the $\mathrm{MgO}$ content increases. Indeed at $100 \%$ magnesium substitution there seems to be no evidence of crystallisation.

\footnotetext{
**Fig. $12 * *$
}

It is suggested that magnesium suppresses crystallisation. Crystallisation of a bioactive glass is known to inhibit its bioactive properties due to the lower reactivity 
of the crystalline state and increased resistance to the ion exchange reaction [59]. Realising that magnesium acts to inhibit crystallinity is extremely important with respect to the bioactivity of the glass structure. Properties such as $T_{g}$ and $T_{c}$ are also critical for the engineering of bioactive glasses with a large window between $\mathrm{T}_{\mathrm{g}}$ and $\mathrm{T}_{\mathrm{c}}$ essential in ensuring that the glasses sinter well without crystallisation. The experimental decrease in $T_{g}$ and increase in $T_{c}$ with magnesium substitution resulting in a large sintering window, also noted by Brink et al. [18] is again extremely beneficial with respect to bioactive glass design for biological implants.

\section{Conclusion}

Glasses were designed with a systematic substitution of $\mathrm{CaO}$ for $\mathrm{MgO}$, on a molar basis, with constant network connectivity throughout the series.

The ${ }^{31} \mathrm{P}$ MAS NMR spectra illustrated a single symmetric resonance with a chemical shift range in the region of 8.2-12.7ppm corresponding to the existence of an orthophosphate environment. No evidence existed for Si-O-P bonding within the bioactive glass. A downfield shift, towards a sodium orthophosphate type species, was observed on substitution of magnesium, implying preferential association of sodium ions with the phosphate phase.

The ${ }^{29} \mathrm{Si}$ MAS NMR data demonstrated the presence of a predominant $\mathrm{Q}^{2}$ structure (-79ppm) with a progressive shift to a $\mathrm{Q}^{3}$ structure (-90ppm) with increasing $\mathrm{MgO}$ substitution. This provided evidence for magnesia acting more as an intermediate oxide than a modifier, with a proportion entering the silicate network as tetrahedral $\mathrm{MgO}_{4}$ species.

Analysis of the physical properties further supported this hypothesis with a decrease in $\mathrm{T}_{\mathrm{g}}$ and $\mathrm{T}_{\mathrm{s}}$ and increase in TEC all highlighting the move to a much weaker 
glass structure with the substitution of magnesium. Both density and TEC values were observed to stray from their relative models (Doweidar and Appen respectively) at $>20$ mole $\%$ substitution implying that magnesium oxide is switching from a modifier to an intermediate through the series.

It is concluded that there is evidence that part of the magnesium oxide is acting as a network intermediate and entering the silicate network $(\approx 14 \%$ in the glasses studied). It is suggested that $\mathrm{MgO}$ can only switch to the role of an intermediate oxide in highly disrupted silicate glasses, of which bioactive glasses are an example - this hypothesis, however warrants further investigation. The effect on the bioactive behaviour is a necessary extension to this work and in the case of this series of glasses is currently under investigation. It is suggested that the intermediate nature of $\mathrm{MgO}$, and its polymerising effect, would ultimately act to decrease the resultant bioactivity. However, it was also discovered that magnesium acts to aid the sintering window or 'working range' $\left(\mathrm{T}_{\mathrm{x}}-\mathrm{T}_{\mathrm{g}}\right)$ and suppress crystallisation, both very beneficial properties with respect to bioactivity.

Although magnesium is an element often found within bioactive glasses there is little understanding of the composition-structure-property relationships within such compositions. This study has enabled us to gain an insight into such relationships, however further investigation and clarification on its structural behaviour and resultant effect on bioactivity is essential. 


\section{Acknowledgements}

The authors would like to thank the EPRSC (grant No. EP/C549309/1) for S.J.W. and M.O.O'D for providing the funding for this work. 
Table Captions

Table 1: Glass compositions (nominal batched) of the magnesium substituted glasses in mole \%. Magnesium is substituted for calcium on a molar basis, keeping the network connectivity (NC) constant - where NC is the network connectivity assuming the phosphate enters the silicate network, $\mathrm{NC}^{\prime}$ assuming a separate orthophosphate phase and NC(NMR) calculated from the ${ }^{29} \mathrm{Si}$ NMR peak fitting in Table 2. To simplify the calculations for $\mathrm{NC}(\mathrm{NMR})$ it is assumed that $\mathrm{Mg}$ is only present as tetrahedral, $\mathrm{MgO}_{4}$ units.

Table 2: The NMR data for ${ }^{29} \mathrm{Si}$ and ${ }^{31} \mathrm{P}$ NMR spectra of the series of magnesium containing bioactive glasses where: $x$ corresponds to peak position, $w$ peak width and $A$ fraction area determined form peak deconvolution. 
Figure Captions

Fig. 1: ${ }^{31} \mathrm{P}$ MAS NMR spectra. Increasing magnesium content from bottom to top, ICIE1 (bottom) to ICIE1-100Mg (top). This illustrates the existence of orthophosphate species and the progressive preferential association of sodium.

Fig. 2: The effect of ${ }^{31} \mathrm{P}$ orthophosphate shift with increase in magnesium content (while sodium content remains constant). This illustrates the progressive preferential association of sodium with the phosphate through the series.

Fig. 3: ${ }^{29}$ Si MAS NMR spectra. Increasing magnesium content from bottom to top, ICIE1 (bottom) to ICIE1-100Mg (top). This illustrates the progressive formation of a $\mathrm{Q}^{3}$ shoulder on a predominantly $\mathrm{Q}^{2}$ peak.

Fig. 4: Cartoon of the glass structure. This illustrates the two regions within the glass with (a) magnesium within the silicate network as tetrahedral $\mathrm{MgO}_{4}$ units charge balanced by calcium and (b) sodium associated with the orthophosphate species. 
Fig. 5: Network connectivity calculated from NMR peak fitting (Table 2) (NC(NMR)) compared to network connectivity assuming $\mathrm{MgO}$ acts as modifier (NC'). In the $\mathrm{NC}$ ' calculation, it was assumed that $\mathrm{Mg}$ is only in a tetrahedral state. The equation of the line is for $\mathrm{NC}(\mathrm{NMR})$.

Figure 6: The absolute amount of $\mathrm{MgO}$ (mol. \%) entering the glass network with $\mathrm{Mg}$ substitution. This assumes that the $\mathrm{MgO}$ is only in tetrahedral co-ordination. As the $\mathrm{MgO}$ content is increasing across the series, this corresponds to a constant proportion $(\approx 14 \%)$ of $\mathrm{MgO}$ acting as network former compared to network modifying $\mathrm{MgO}$.

Fig. 7: Differential Thermal Analysis (DTA) traces for the magnesium substituted series of glasses. Increasing magnesium content from ICIE1 (top) to ICIE1-25Mg to ICIE1-100Mg to ICIE1-50Mg to ICIE1-75Mg (bottom).

Fig. 8: Graph of glass transition temperature, $\mathrm{T}_{\mathrm{g}}$ (bottom line) and softening temperature, $\mathrm{T}_{\mathrm{s}}$ (top line) against percentage of magnesium substituted. Illustrates the decreasing trend in $\mathrm{T}_{\mathrm{g}}$ and $\mathrm{T}_{\mathrm{s}}$ with magnesium substitution.

Fig. 9: Graph of experimental thermal expansion coefficients, (TEC) (top) and Appen's predictions (bottom) against percentage of magnesium substituted. This illustrates the difference between Appen's predicted decreasing trend and the experimental increase in TEC with magnesium substitution. 
Fig. 10: Graph of experimental density values (top) and Doweidar's predictions (bottom) against percentage of magnesium substituted. This illustrates decreasing trend in experimental and Doweidar's predicted density values with magnesium substitution.

Fig. 11: Graph of oxygen density against percentage of magnesium substituted. Illustrates increasing trend in oxygen density with magnesium substitution.

Fig. 12: Graph of crystallisation temperature $\left(\mathrm{T}_{\mathrm{c}}\right)$ against percentage of magnesium substituted. Illustrates increasing trend in $\mathrm{T}_{\mathrm{c}}$ with magnesium substitution. 
Table 1

\begin{tabular}{|c|c|c|c|c|c|c|c|c||}
\hline Glass ID & $\mathbf{S i O}_{2}$ & $\mathbf{N a}_{2} \mathbf{O}$ & $\mathbf{C a O}$ & $\mathbf{P}_{2} \mathbf{O}_{\mathbf{5}}$ & $\mathbf{M g O}$ & $\mathbf{N C}$ & NC' & NC(NMR) \\
\hline ICIE1 & 49.46 & 26.38 & 23.08 & 1.07 & 0.00 & 2.04 & 2.13 & 2.17 \\
\hline ICIE1-25Mg & 49.46 & 26.38 & 17.31 & 1.07 & 5.77 & 2.04 & 2.13 & 2.20 \\
\hline ICIE1-50Mg & 49.46 & 26.38 & 11.54 & 1.07 & 11.54 & 2.04 & 2.13 & 2.23 \\
\hline ICIE1-75Mg & 49.46 & 26.38 & 5.77 & 1.07 & 17.31 & 2.04 & 2.13 & 2.32 \\
\hline ICIE1-100Mg & 49.46 & 26.38 & 0.00 & 1.07 & 23.08 & 2.04 & 2.13 & 2.41 \\
\hline
\end{tabular}


Table 2

\begin{tabular}{|c|c|c|c|c|c|c|c|c|}
\hline Glass ID & $\begin{array}{l}{ }^{31} \mathbf{P} x \\
(\mathbf{p p m})\end{array}$ & $\begin{array}{c}{ }^{31} \mathbf{P} w \\
(\mathbf{H z})\end{array}$ & $\begin{array}{l}{ }^{29} \mathrm{Si} \mathrm{Q}^{2} x \\
(\mathrm{ppm})\end{array}$ & $\begin{array}{c}{ }^{29} \mathrm{Si} \mathrm{Q^{2 }} w \\
(\mathrm{~Hz})\end{array}$ & $\begin{array}{c}{ }^{29} \mathrm{Si} Q^{2} A \\
(\%)\end{array}$ & $\begin{array}{c}{ }^{29} \mathrm{Si} \mathrm{Q}^{3} x \\
(\mathrm{ppm})\end{array}$ & $\begin{array}{c}{ }^{29} \mathrm{Si} \mathrm{Q^{3 }} w \\
(\mathbf{H z})\end{array}$ & $\begin{array}{c}{ }^{29} \mathrm{Si} \mathrm{Q}^{3} A \\
(\%)\end{array}$ \\
\hline ICIE1 & 8.2 & 687 & -80.6 & 461 & 83 & -89.8 & 316 & 17 \\
\hline $\begin{array}{l}\text { ICIE1- } \\
25 \mathrm{Mg}\end{array}$ & 9.7 & 526 & -79.4 & 399 & 80 & -87.6 & 258 & 20 \\
\hline $\begin{array}{l}\text { ICIE1- } \\
50 \mathrm{Mg}\end{array}$ & 10.5 & 639 & -80.6 & 451 & 77 & -90.3 & 376 & 23 \\
\hline $\begin{array}{l}\text { ICIE1- } \\
75 \mathrm{Mg}\end{array}$ & 11.7 & 642 & -80.1 & 410 & 68 & -88.8 & 433 & 32 \\
\hline $\begin{array}{l}\text { ICIE1- } \\
100 \mathrm{Mg}\end{array}$ & 12.7 & 642 & -80.0 & 396 & 59 & -88.7 & 424 & 41 \\
\hline
\end{tabular}




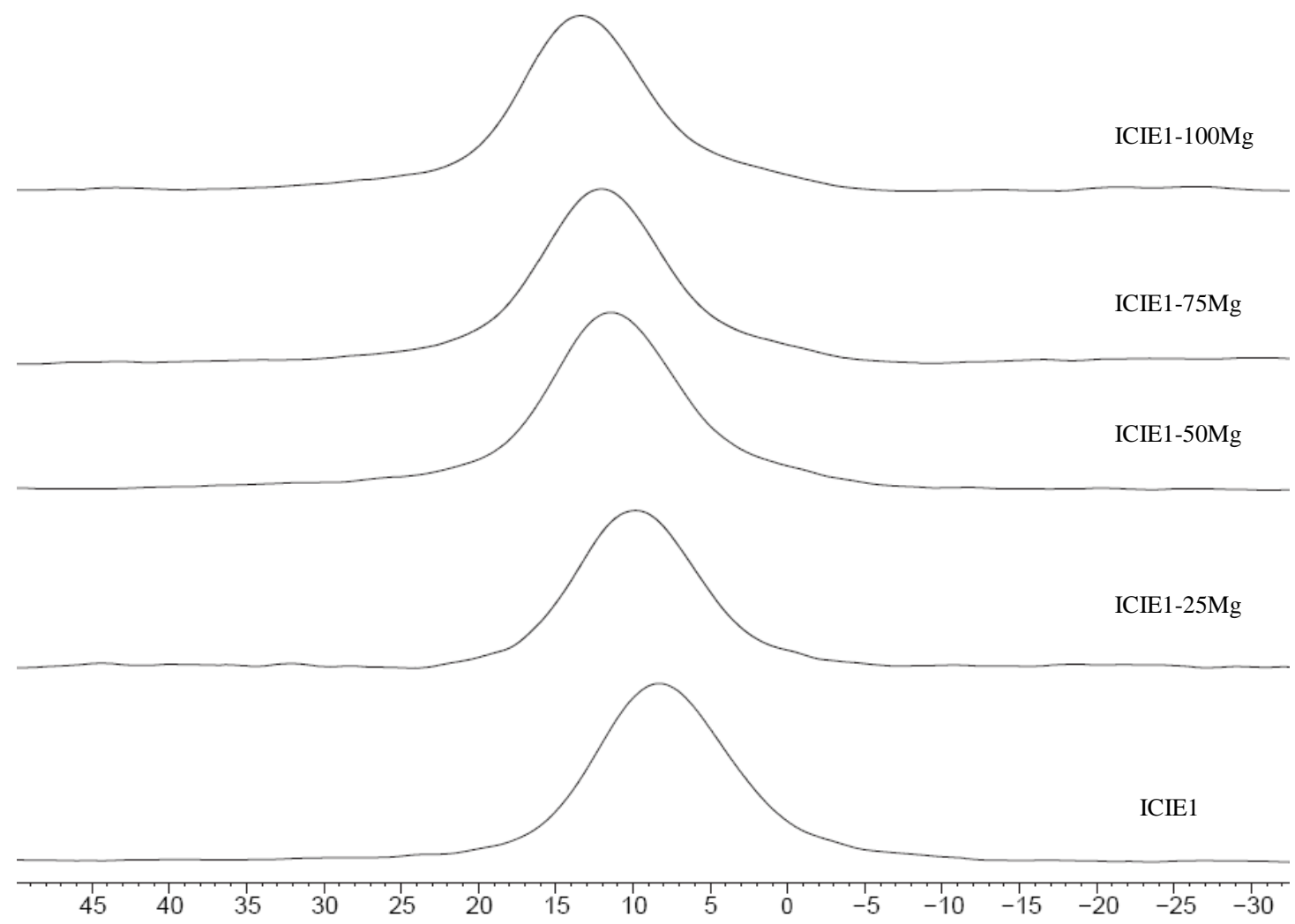

Fig. 1 


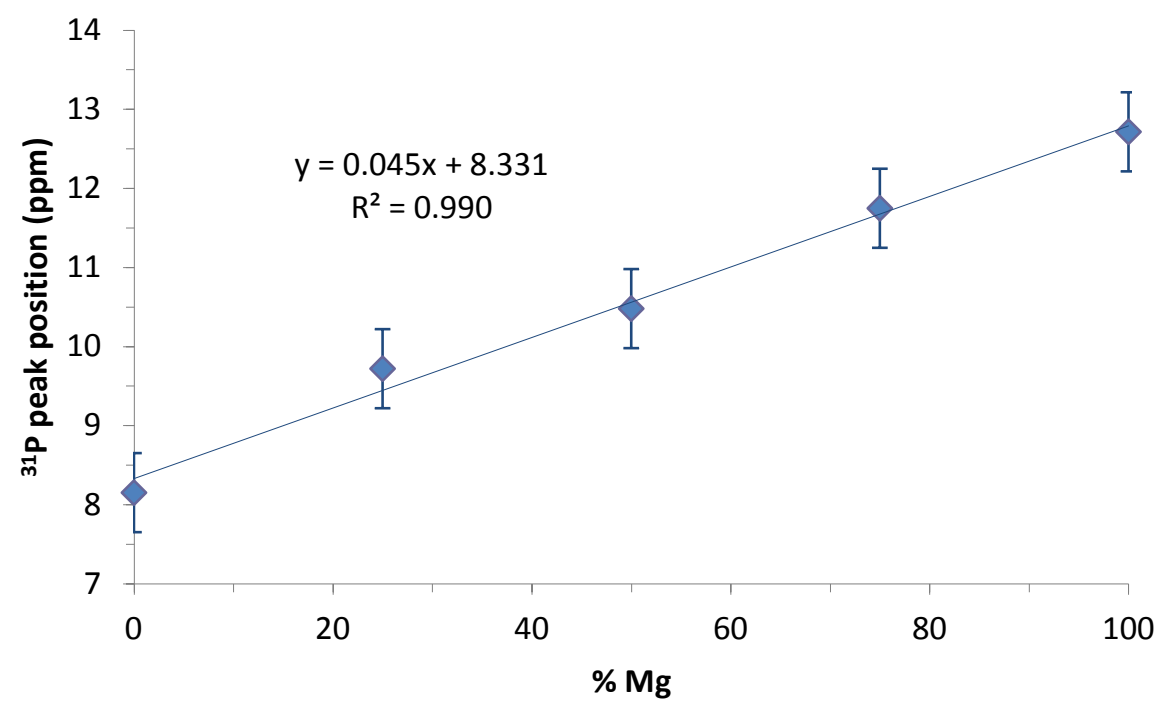

Fig. 2 


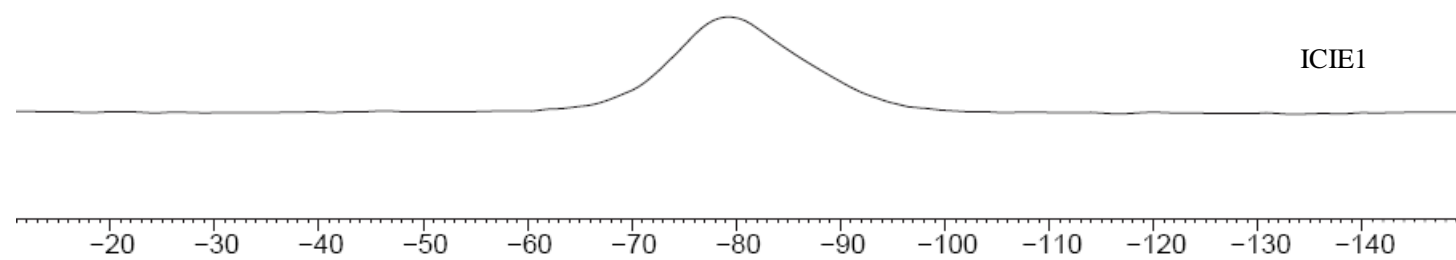

Fig. 3 


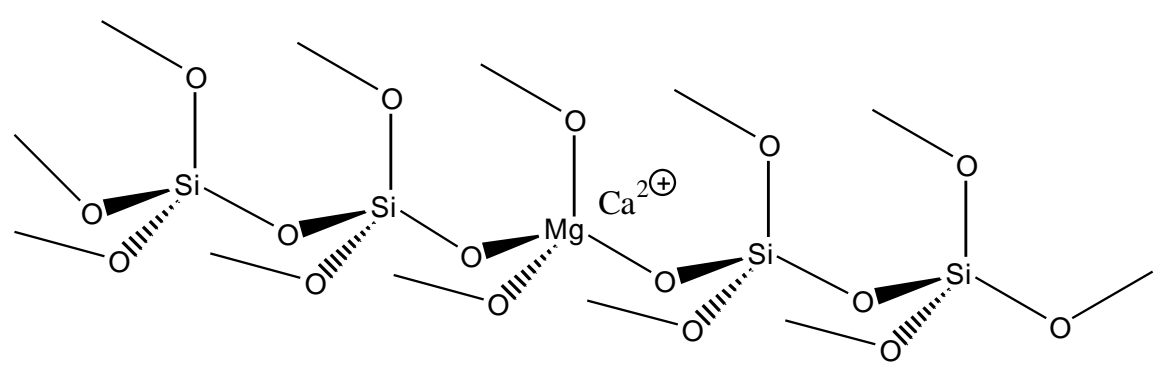

(a)

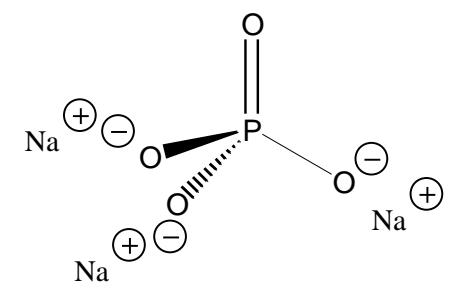

(b)

Fig. 4 


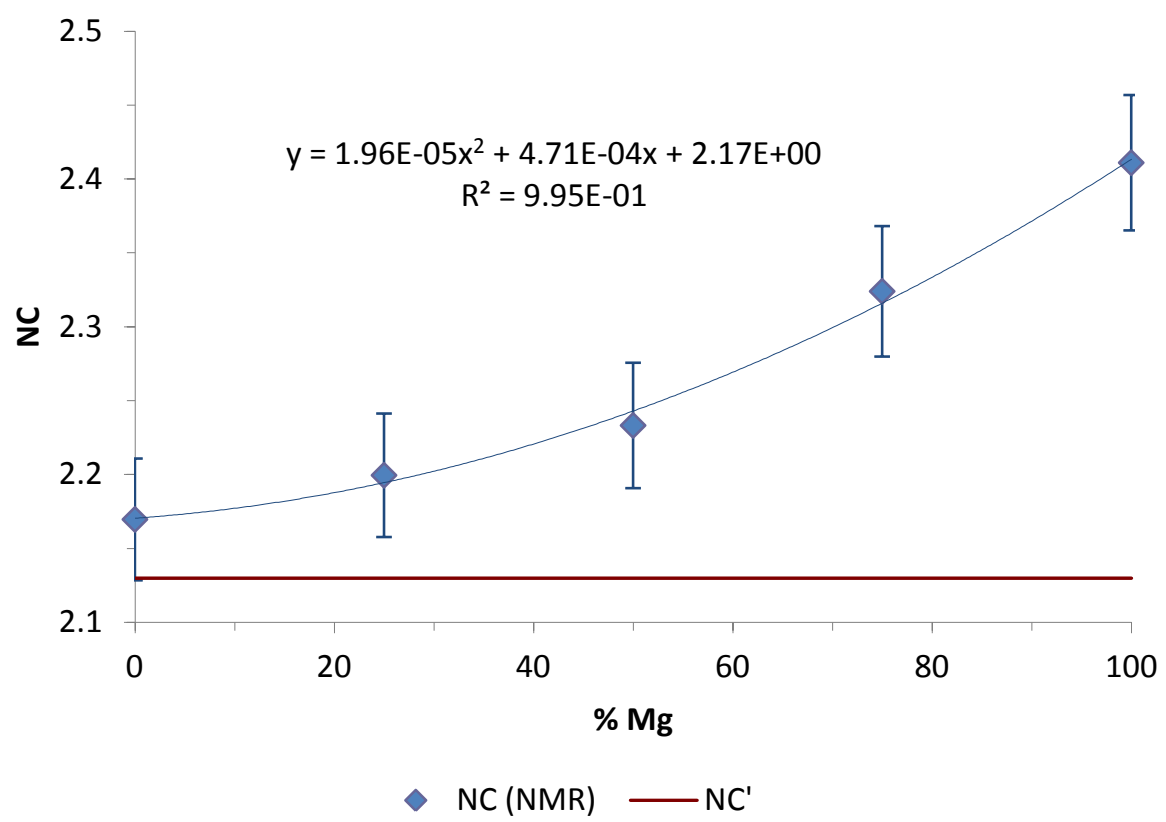

Fig. 5 


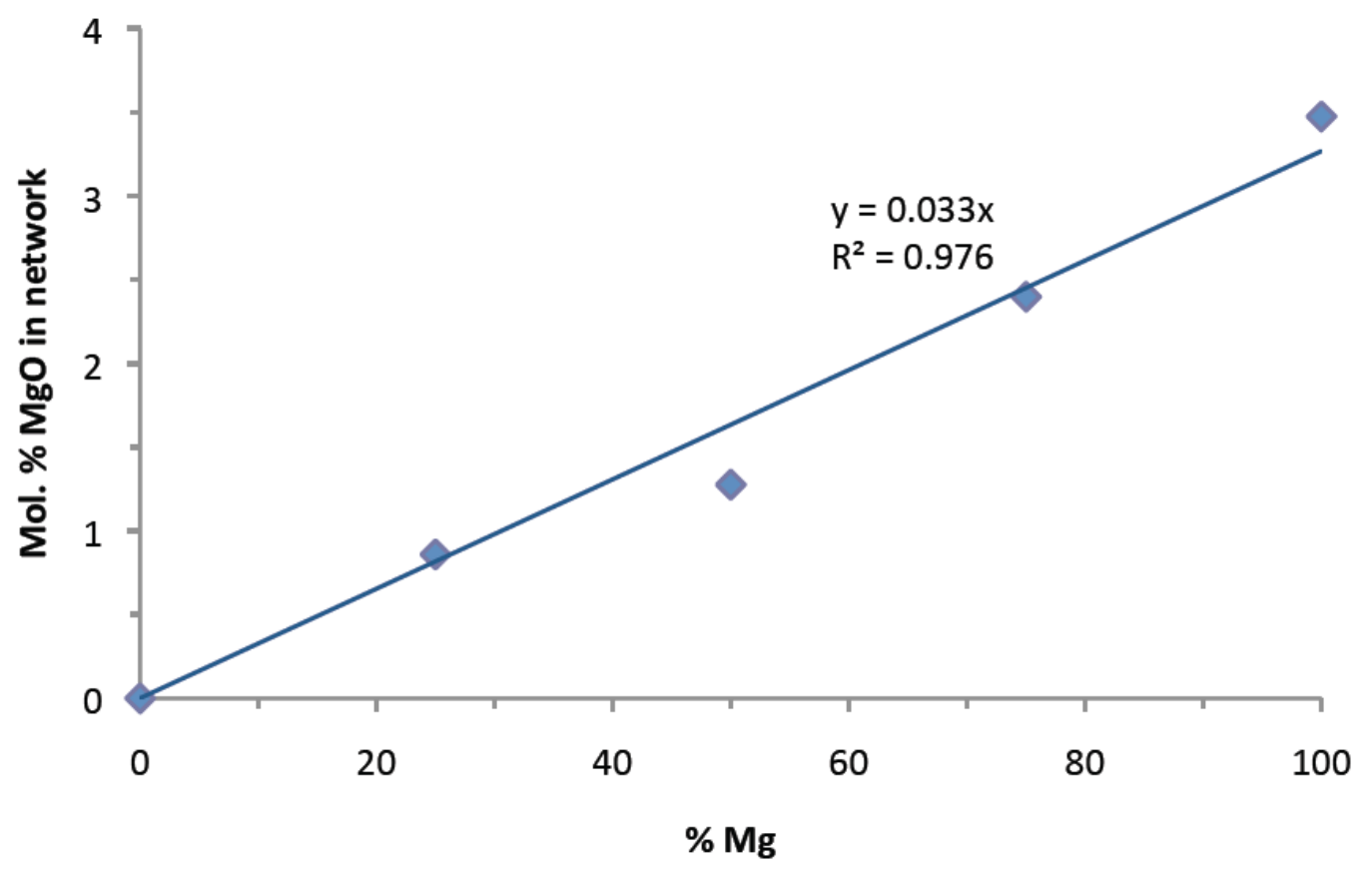

Fig. 6 


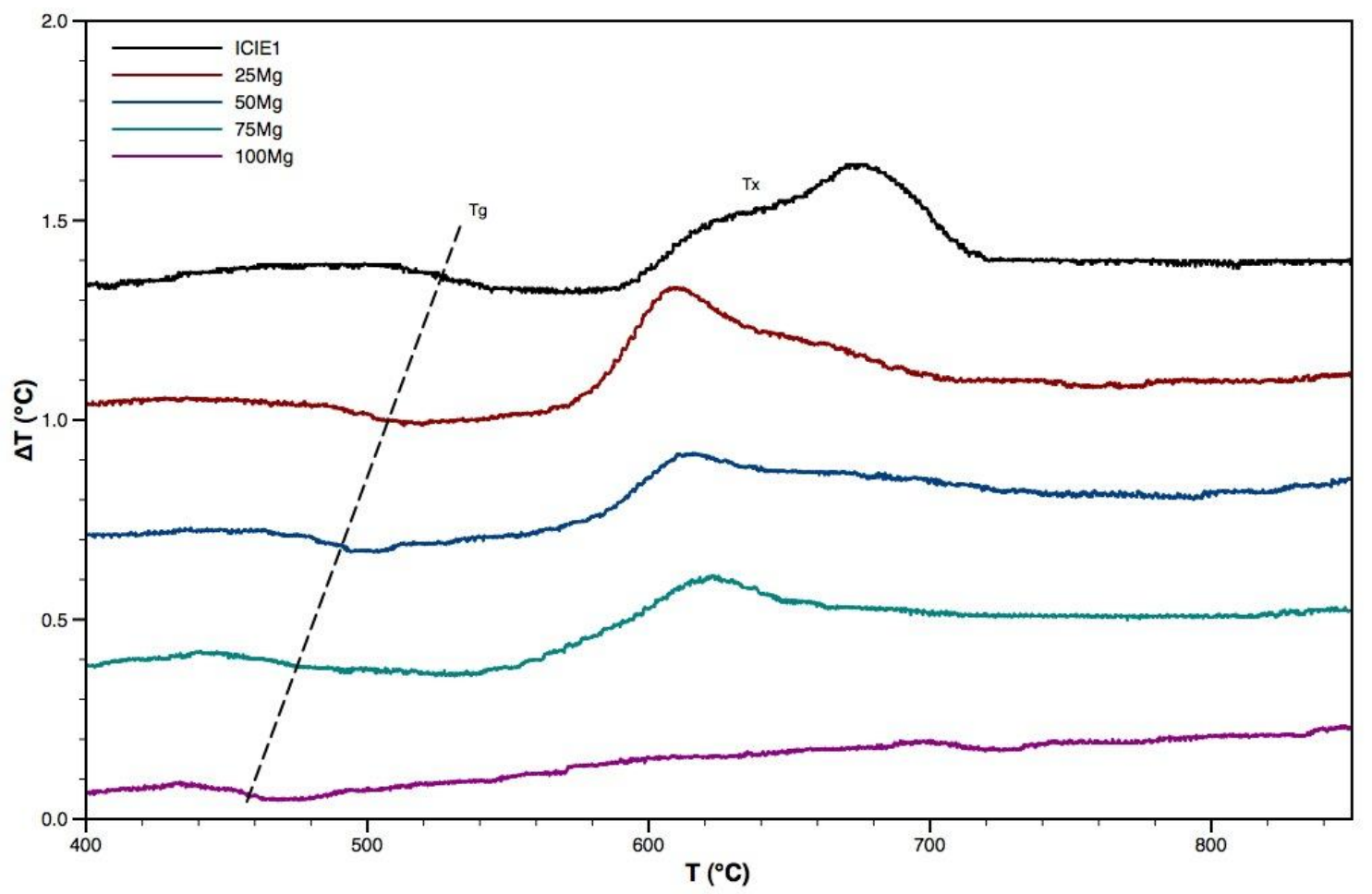

Fig. 7 


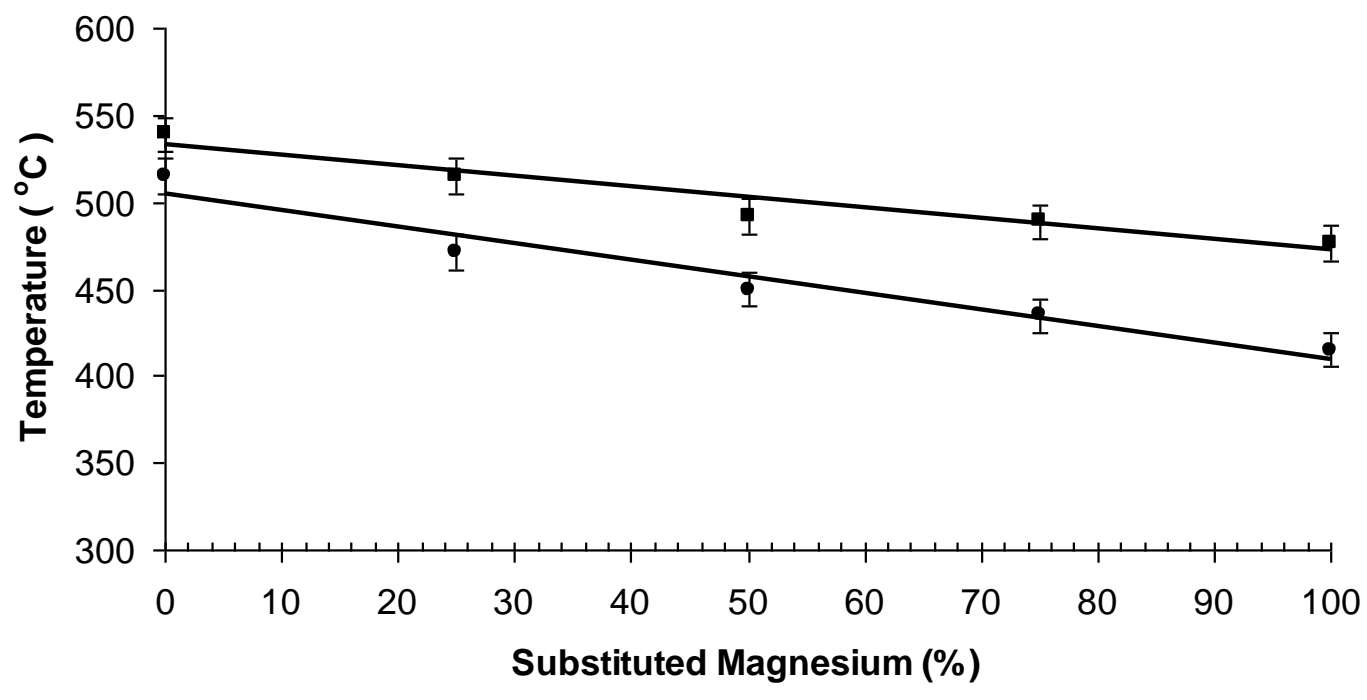

Fig. 8 


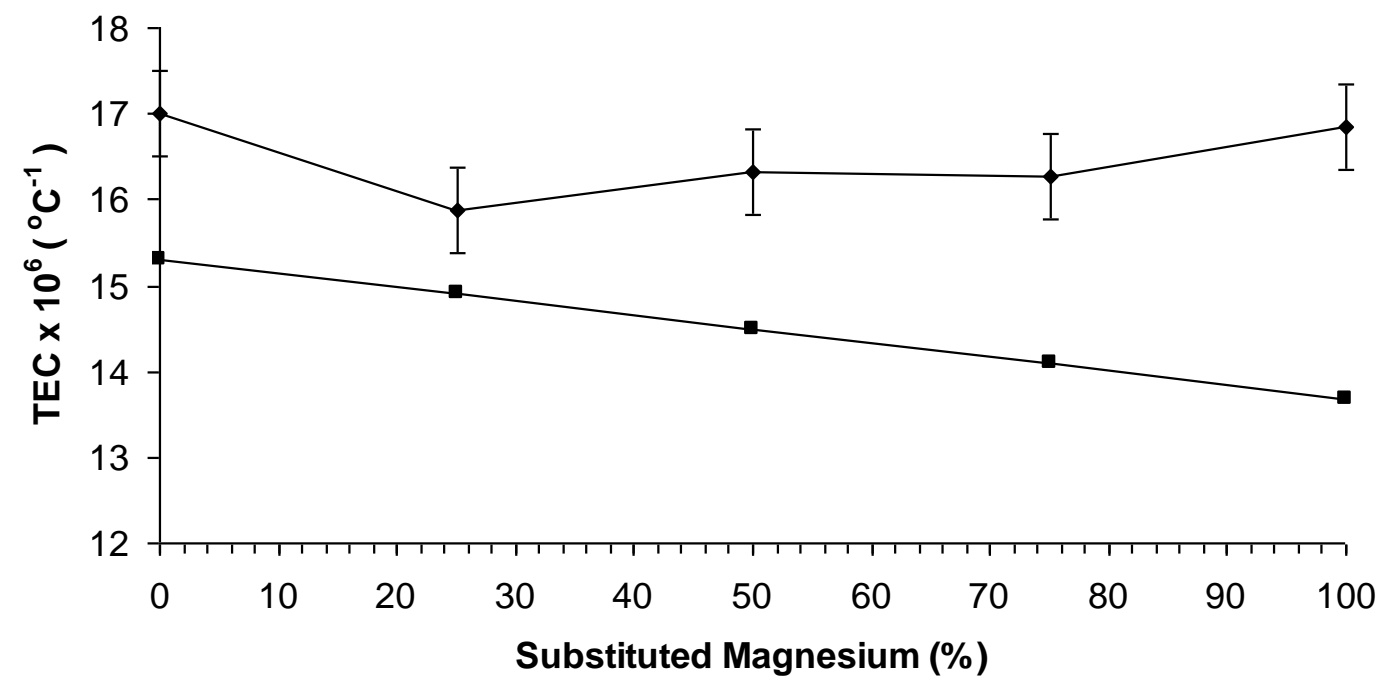

Fig. 9 


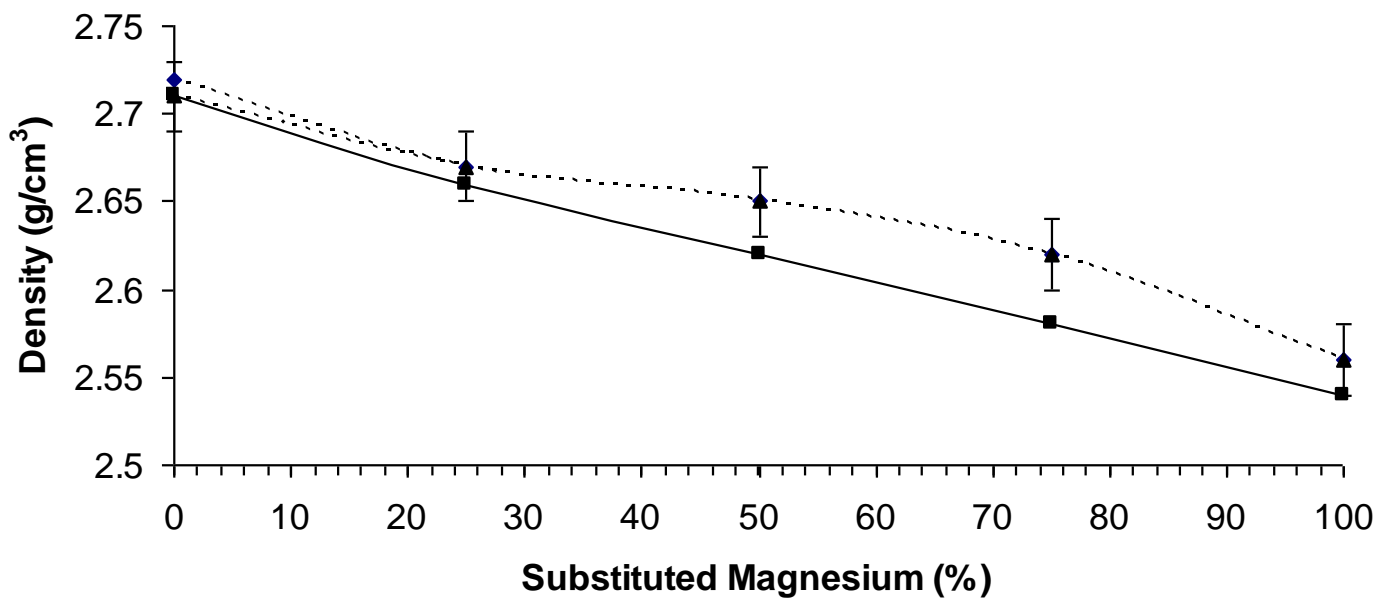

Fig. 10 


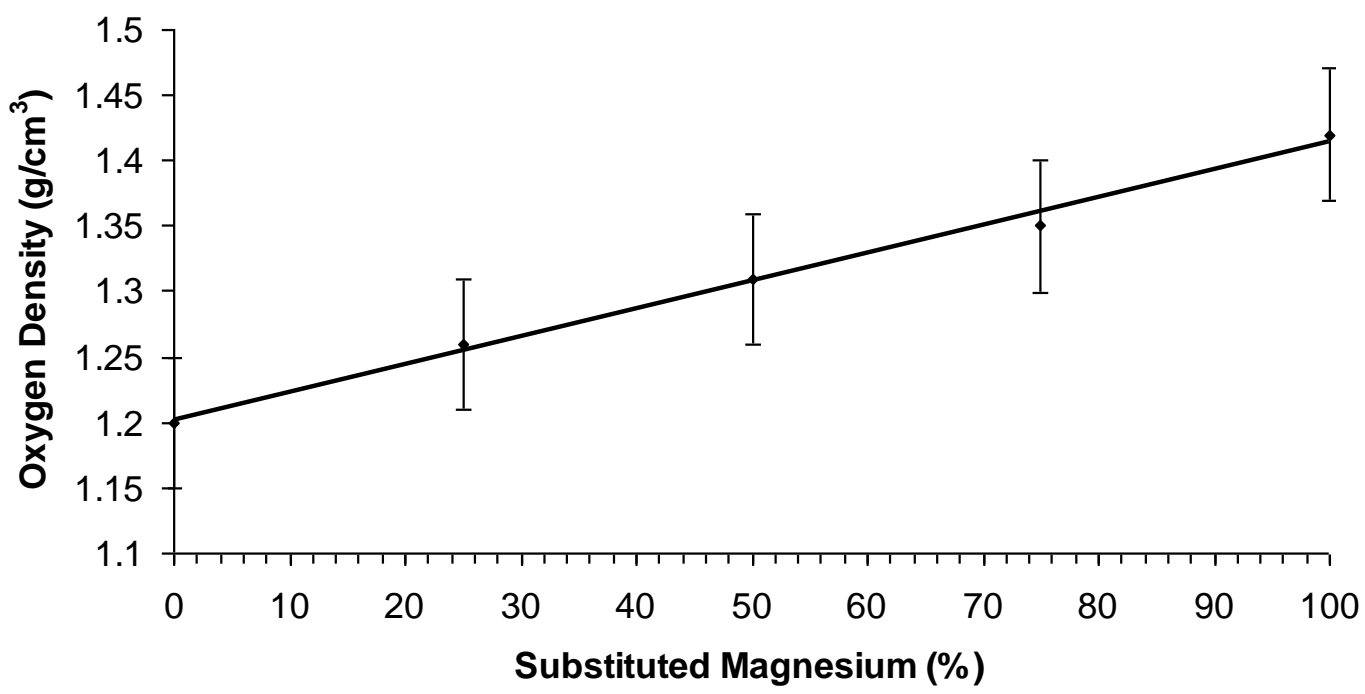

Fig. 11 


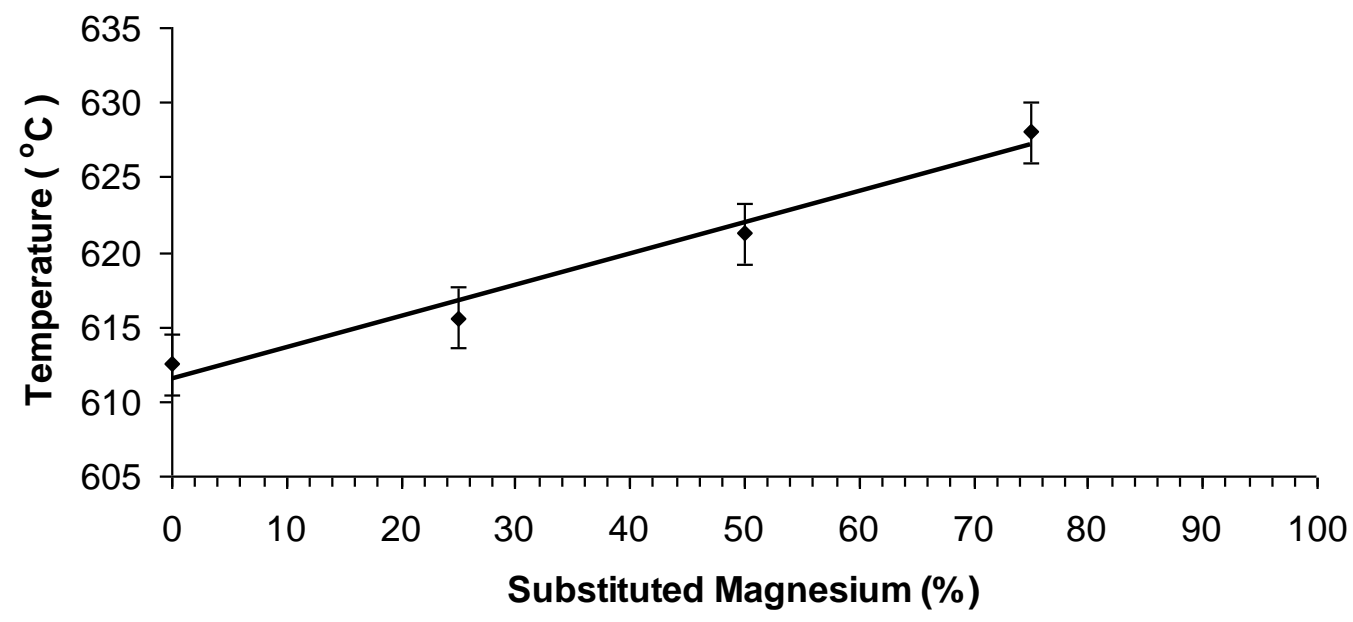

Fig. 12 


\section{References}

[1] I. Elgayar, PhD Thesis: The Influence of Alkali Metal Content and Network Connectivity on Bioctive Glasses, Imperial College of Science, Technology and Medecine, London (2004).

[2] M. R. Towler, K. T. Stanton, P. Mooney, R. G. Hill, N. Moreno and X. Querol, Journal of Chemical Technology and Biotechnology, 77, (2002) 240.

[3] M. W. G. Lockyer, D. Holland and R. Dupree, J. Non-Cryst. Solids, 188, (1995) 207.

[4] J. B. Murdoch, J. F. Stebbins and I. S. E. Carmichael, Am. Mineral., 70, (1985) 332.

[5] I. Elgayar, A. E. Aliev, A. R. Boccaccini and R. G. Hill, J. Non-Cryst. Solids, 351, (2005) 173.

[6] L. L. Hench, T. K. Greenlee, R. J. Splinter, W.C. Allen, J. Biomed. Mater. Res. Symp. 2., 2, (1971) 117.

[7] L. L. Hench and H. A. Paschall, J. Biomed. Mater. Res., 7, (1973) 25.

[8] T. Kokubo, H. Kushitani, C. Ohtsuki, S. Sakka and T. Yamamuro, J. Mater. Sci. - Mater. Med., 3, (1992) 79.

[9] O. H. Andersson, K. H. Karlsson and K. Kangasniemi, J. Non-Cryst. Solids, 119, (1990) 290.

[10] P. Li, Q. Yang, F. Zhang and T. Kokubo, J. Mater. Sci. - Mater. Med., 3, (1992) 452.

[11] R. G. Hill, J. Mater. Sci. Lett., 15, (1996) 1122.

[12] K. Wallace, PhD Thesis: Design of Bioactive Glass Compositions, University of Limerick (2000).

[13] Z. Strnad, Biomaterials, 13, (1992) 317.

[14] R. D. Rawlings, J. Mater. Sci. Lett., 11, (1992) 1340.

[15] L. Holliday, Inorganic Macromol. Reu., 1, (1970) 3.

[16] N. H. Ray, Inorganic Polymers, Academic Press, London, 1978.

[17] K. Wallace, Design of Bioactive Glass Compositions, Universtiy of Limerick (2000).

[18] M. Brink, J. Biomed. Mater. Res., 36, (1997) 109.

[19] M. Brink, T. Turunen, R. P. Happonen and A. YliUrpo, J. Biomed. Mater. Res., 37, (1997) 114.

[20] J. M. Gomez-Vega, E. Saiz and A. P. Tomsia, J. Biomed. Mater. Res., 46, (1999) 549.

[21] E. Saiz, M. Goldman, J. M. Gomez-Vega, A. P. Tomsia, G. W. Marshall and S. J. Marshall, Biomaterials, 23, (2002) 3749.

[22] J. M. Oliveira, R. N. Correia and M. H. Fernandes, J. Non-Cryst. Solids, 273, (2000) 59.

[23] J. M. Oliveira, R. N. Correia and M. H. Fernandes, Biomaterials, 23, (2002) 371.

[24] J. M. Oliveira, R. N. Correia, M. H. Fernandez and J. Rocha, J. Non-Cryst. Solids, 265, (2000) 221.

[25] Y. K. Ebisawa, T., J. Mater. Sci. - Mater. Med., 1, (1980) 239.

[26] K. Ohura, T. Nakamura, T. Yamamuro, Y. Ebisawa, T. Kokubo, Y. Kotoura and M. Oka, J. Mater. Sci. - Mater. Med., 3, (1992) 95.

[27] T. Kasuga, K. Nakagawa, M. Yoshida and E. Miyade, J. Mater. Sci., 22, (1987) 3721. 
[28] J. S. Moya, A. P. Tomsia, A. Pazo, C. Santos and F. Guitian, J. Mater. Sci. Mater. Med., 5, (1994) 529.

[29] A. J. Salinas, J. Roman, M. Vallet-Regi, J. M. Oliveira, R. N. Correia and M. H. Fernandes, Biomaterials, 21, (2000) 251.

[30] P. W. McMillan, Glass Ceramics, Academic Press, London, 1979.

[31] P. S. Fiske and J. F. Stebbins, American Mineralogist, 79, (1994) 848.

[32] S. Kohara, K. Suzuya, K. Takeuchi, C. K. Loong, M. Grimsditch, J. K. R. Weber, J. A. Tangeman and T. S. Key, Science, 303, (2004) 1649.

[33] M. A. Karakassides, A. Saranti and I. Koutselas, J. Non-Cryst. Solids, 347, (2004) 69.

[34] A. Dietzel, Elektrochem., 48, (1942) 9.

[35] K. Shimoda, Y. Tobu, M. Hatakeyama, T. Nemoto and K. Saito, Am. Mineral., 92, (2007) 695.

[36] H. Doweidar, J. Non-Cryst. Solids, 249, (1999) 194.

[37] A. A. Spasov, Bulletin of experimental biology and medicine, 131, (2001)

132.

[38] J. E. Sojka, Weaver, C. M., Nutr Rev., 53, (1995) 71.

[39] A. M. George and J. F. Stebbins, American Mineralogist, 83, (1998) 1022.

[40] S. Kroeker and J. F. Stebbins, American Mineralogist, 85, (2000) 1459.

[41] R. Dupree and M. E. Smith, Journal of the Chemical Society-Chemical Communications, (1988) 1483.

[42] R. Ahsan and M. G. Mortuza, Journal of Non-Crystalline Solids, 351, (2005) 2333.

[43] R. Dupree, D. Holland and M. G. Mortuza, Nature, 328, (1987) 416.

[44] I. L. Mudrakovskii, V. P. Shmachkova, N. S. Kotsarenko and V. M. Mastikhin, Journal of Physics and Chemistry of Solids, 47, (1986) 335.

[45] G. L. Turner, K. A. Smith, R. J. Kirkpatrick and E. Oldfield, Journal of Magnetic Resonance, 70, (1986) 408.

[46] M. A. Aramendia, V. Borau, C. Jimenez, J. M. Marinas, F. J. Romero and J. R. Ruiz, J. Sol. State Chem., 135, (1998) 96.

[47] S. N. Scrimgeour, J. A. Chudek, G. A. Cowper and C. H. Lloyd, Dent. Mater., 23, (2007) 934.

[48] P. C. D. Zhang, P. Floriana, P. J. Grandinetti and J. F. Stebbins, J. Non-Cryst. Solids, 204, (1996) 294.

[49] P. Zhang, Grandinetti, P.J., and Stebbins, J.F, J. Phys. Chem. B, 101, 20, 1997) 4004

[50] R. Dupree, Holland, D., Mortuza, M.G., Phys. Chem. Glasses, 29(1), (1988) 18.

[51] A. R. Grimmer, M. Magi, M. Hahnert, H. Stade, A. Samoson, W. Wieker and E. Lippmaa, Phys. Chem. Glasses, 25, (1984) 105.

[52] P. G. Galliano, J. M. P. Lopez, E. L. Varetti, I. Sobrados and J. Sanz, Mater. Res. Bull., 29, (1994) 1297.

[53] E. Dowty, Phys. Chem. Miner., 14, (1987) 122.

[54] J. A. Kerr, CRC Handbook of Chemistry and Physics, CRC Press, Florida, 2000.

[55] L. Linati, G. Lusvardi, G. Malavasi, L. Menabue, M. C. Menziani, P. Mustarelli and U. Segre, J. Phys. Chem. B, 109, (2005) 4989.

[56] Shannon, Act. Cryst A32, (1976) 751.

[57] H. Doweidar, Phys. Chem. Glasses, 40, (1999) 85.

[58] P. G. Galliano, A.L. Cavalier, J. Non-Cryst. Solids, 1995) 311. 
[59] K. E. Wallace, R. G. Hill, J. T. Pembroke, C. J. Brown and P. V. Hatton, J. Mater. Sci. - Mater. Med., 10, (1999) 697. 